\title{
Heart to Heart: A Relation-Alignment Approach to Emotion's Social Effects
}

Brian Parkinson (iD

Department of Experimental Psychology, University of Oxford, UK

\begin{abstract}
This article integrates arguments and evidence from my 2019 monograph Heart to Heart: How Your Emotions Affect Other People. The central claim is that emotions operate as processes of relation alignment that produce convergence, complementarity, or conflict between two or more people's orientations to objects. In some cases, relation alignment involves strategic presentation of emotional information for the purpose of regulating other people's behaviour. In other cases, emotions consolidate from socially distributed reciprocal adjustments of cues, signals, and emerging actions without any explicit registration or communication of emotional meaning by parties to the exchange. The relation-alignment approach provides a fresh perspective on issues relating to emotion's interpersonal, intragroup, and organizational functions and clarifies how emotions are regulated for social purposes.
\end{abstract}

\section{Keywords}

emotion regulation, relation alignment, social appraisal, social functions

Emotions carry consequences that extend beyond any single individual. Another person's anger, love, or hate is difficult to ignore even when it is not directed at us. When someone nearby is delighted or distressed about anything, their emotion seems to carry a gravitational pull that draws us in.

Why are other people's emotions so compelling? How do they achieve their social effects? My book Heart to Heart presents an integrative approach to the underlying processes based on the idea of relation alignment - the mutual positioning of two or more interacting individuals who are oriented to a person, object, or event from similar or different angles. Emotions serve to calibrate those individuals' respective orientations to what is happening, either by conveying appraisals and action tendencies from person to person or by providing a dynamic stream of bodily nudges and implicit attentional cues to which other people's orientations adjust in real time.

The relation-alignment approach is best understood as an alternative to traditional single-minded analyses of emotional functioning, which see social effects as necessarily secondary to more fundamental individual processes. The next section of this article compares and contrasts these two approaches. Subsequent sections set out the verbal and nonverbal channels along which emotions operate between people, and the implications of the relation-alignment approach for our understanding of emotion's interpersonal and intragroup effects and social-regulatory functions.

\section{Emotions and Their Social Effects: Inside Out or Outside In?}

What's at the heart of emotion? Philosophers and psychologists have attempted to identify the phenomenon's defining characteristics and distinctive causes for centuries (see Solomon, 2003). Working from the assumption that emotional states primarily reside within individual minds or bodies, they have attempted to identify the specific mental or physiological ingredients that supposedly add emotional colour and quality to personal experience (Parkinson, 2013). This project leads to the conclusion that emotions depend on cognitive appraisal (e.g., Lazarus, 1991), interoceptive feedback (e.g., James, 1884; Laird \& Bresler, 1992), or both (e.g., Schachter, 1964). From the relation-alignment perspective, this long-standing research tradition gets things inside out (Crivelli \& Fridlund, 2019). Rather than individual mental or bodily states, emotions are fundamentally relational processes (e.g., Frijda, 1986) distributed between people (de Rivera \& Grinkis, 1986) who are orienting dynamically to each other and their shared environment. 
Even research into social effects and functions usually presupposes that emotions are primarily internal events that only indirectly surface in the external arena. From this perspective, social influence involves the translation of subjective meaning into publicly detectable symptoms, signals, or symbols (e.g., Bühler, 1934/2011). For example, emotion may be communicated in words or facial expressions but neither of these channels provides unobstructed access to the underlying phenomenon itself: Words need not map onto basic emotion categories and faces get regulated in accordance with display rules (e.g., Ekman, 1972). Other people can only respond to the indirect and potentially distorted emotional information conveyed by verbal and nonverbal cues.

If emotions are instead forms of social-relational activity, their influence on others is already built into their functional operation. Speech acts and bodily movements may be part of an emerging strategy of coregulation rather than representations or manifestations of separate private meanings. In the following sections of this article, I consider approaches to verbal and nonverbal emotion communication that acknowledge their interpersonal orientation and pragmatic functions. I then consider the implications of the relation-alignment perspective for understanding the interpersonal effects of emotion, and for developing an integrative account of emotion regulation and emotional function that contextualizes dyadic processes in group and organizational life.

\section{Getting Across From Heart to Heart}

Individualistic approaches usually treat words and facial movements as indirect representations of internal emotional states. Emotional meaning thus needs to be translated into a socially accessible medium before being transmitted to other people. In this section, I argue that this assumption underestimates the importance of the pragmatic functions of verbal and nonverbal communication in emotional interactions. Rather than simply carrying semantic meaning, words and faces are intrinsic constituents of the processes whereby relations between people become aligned. They don't just represent or express emotions, they exert social pressure and thereby help to construct the emotional process in the first place.

\section{Verbal Communication}

Most psychological research into emotional language focuses on descriptive meanings of nouns and adjectives. When comparing and classifying these words in explicit terms, participants rarely draw clear boundaries around the categories that they supposedly denote. Laypeople's representations of specific emotions such as "anger" (Russell \& Fehr, 1994) and the more general concept of "emotion" (Fehr \& Russell, 1984) seem fuzzy, inconsistent, and underdefined. These findings are consistent with proposals that everyday emotion concepts are represented either as scripts that set out the sequence of events unfolding in a prototypical instance of the relevant emotional episode (e.g., Kövecses, 1990; Russell \& Fehr, 1994; Shaver et al., 1987), or as populations of context-dependent perceptual simulations (e.g., Barrett, 2017). In the light of this evidence, theorists who wish to maintain that emotions themselves are distinct psychological processes or states are forced to conclude that any society's vernacular language provides at best imperfect representations of them (e.g., Scarantino \& Griffiths, 2011). An alternative conclusion is that emotional language is not primarily designed for descriptive purposes in the first place (e.g., Edwards, 1999).

The studies discussed in the previous paragraph all treat emotion words as decontextualized carriers of semantic meaning rather than as part of more articulated communicative and social influence processes. In the hurly-burly of ordinary conversations, any apparent imprecision or multiplicity of reference may in fact reflect an inherent flexibility that allows emotional language to achieve a variety of pragmatic functions in interpersonal and institutional dialogues.

Taking such a discursive perspective, Edwards (1999) specifically takes issue with the assumption that emotion words are associated with preexisting mental concepts that pick out more or less definite objects in the psychological world. He argues instead that emotion talk always presents a specific formulation of events that is selected from a range of possible alternatives to achieve particular conversational functions. This socially attuned formulation may then be accepted, reworked, or contested by the person at whom it is addressed. According to Edwards's account, then, using an emotion word is not about finding the most accurate description of something that is already there. Instead, it helps to build a version of events that supports a situated argumentative position.

A key inspiration for this kind of discursive approach is Austin's (1962) classic analysis of performative speech acts (see also Potter \& Wetherell, 1987; Scarantino, 2017). Instead of considering what individual words mean on the semantic level, Austin focused on what pragmatic consequences linguistic statements achieve when delivered in appropriate social contexts. Talking can directly perform social actions when someone christens a baby, pleads "guilty," or accepts a wager. But performative speech acts are not restricted to these formal contexts. People also use words to accuse or condemn someone, and to make commitments or bets outside the courtrooms, churches, or casinos where officially sanctioned linguistic practices take place.

What kinds of things does emotion language do apart from simply describing what is going on? One answer was offered by Bedford (1957), who wrote that "emotion words form part of the vocabulary of appraisal and criticism" (p. 294). From his perspective, speakers use first-person emotional statements to present interpretations and evaluations of what is happening. For example, saying "I am angry" allocates blame to someone or something, and saying "I am afraid" confers threatening qualities on an object, event, or person. Both utterances encourage addressees to adjust their own orientation accordingly, by also blaming the object of communicated "anger" or attending to the threat identified by communicated "fear," respectively.

The point of conveying emotion depends on who the addressee might be. When presenting myself as "angry" to the person blocking my progress, the point is to ward or warn them 
off, to threaten serious consequences if they don't budge, shift, or buckle. When presenting my anger to a potential ally, the point is to bring them onside, to get them to agree that someone else is in the wrong, or to get them to help dislodge whatever blockage I am confronting.

What gives emotion statements their power to achieve these pragmatic effects? One possible explanation draws on the idea of preference structures developed in the field of conversation analysis (e.g., Levinson, 1983). According to this account, speech acts are generally organized in two-part call-response sequences ("adjacency pairs"; Sacks, 1992). Delivery of the first part of an adjacency pair serves to restrict the range of socially permissible responses that are available to the addressee in the second part. For example, the most relevant response to a question is an answer, so asking someone a question normatively encourages them to provide an answer.

When two or more possible responses to the first part of an adjacency pair are equally relevant, one is usually more normatively appropriate than others. For example, if someone invites you to a party, agreeing to attend is the "preferred" response (Pomerantz, 1984), meaning that your acceptance can be delivered immediately and without equivocation. However, if you are unable or unwilling to accede, declining the invitation requires more conversational work (i.e., it is a relevant but "dispreferred" option). Instead of replying immediately, you may pause, and this pause both indicates potential conversational trouble and provides the inviter with an opportunity to release you from any implied obligation to accept ("well, of course, only if you don't have other commitments"). Or you may present an elaborate excuse, apology, or counter-offer ("I'd love to, but unfortunately ..."). Baldly declining an invitation without marking your failure to co-operate with the inviter's expressed wishes would be recognizably impolite (e.g., Brown \& Levinson, 1987).

When the first part of an adjacency pair presents the speaker's judgement about anything, the preferred second part involves the addressee agreeing with that judgement (Levinson, 1983). By extension, the preferred response to any appraisal communicated by an emotional statement should endorse that appraisal. Thus, if you say that you blame me for something or that you are angry about it, the path of least interpersonal resistance is for me to acknowledge that I am blameworthy. Any attempt to counter or deflect blame would be a relevant but dispreferred option requiring further elaboration and effort on my part. In other words, the socially prescribed reply to an angry claim about my blameworthiness is to apologize or communicate that I feel suitably guilty (which in turn encourages a forgiving response from you). More generally, first-person emotion statements that take the addressee as their object (e.g., "I am angry with you" or "I love you") encourage responses that communicate complementary or matching emotions (e.g., "I feel guilty" or "I love you too," respectively).

When the addressee of an emotional speech act is not the target of the communicated emotion, the statement encourages the addressee to align their orientation towards the emotion's object with the stance taken by the speaker (cf. social referencing; e.g., Parkinson, 2019; Sorce et al., 1985). Thus, communicated anger about a third party normatively constitutes an appeal for emotional corroboration in the form of explicit agreement that the person acted in a reprehensible way and shared anger about their conduct. In other words, an object-directed emotion statement typically encourages the addressee to respond by communicating a matching or convergent orientation to the object of the presented emotion.

Nothing about the flexible organization of adjacency pairs directly compels addressees to align their verbal emotion communications with those presented by speakers. The pressure to succumb to the force of a speech act depends on norms that are backed up only by potential negative social implications of nonconformity. At some level, addressees are sensitive to the fact that breaching conversational convention brings consequences. In the short term, their interaction is likely to proceed more smoothly if they deliver a preferred response. In the longer term, repeated inappropriate responses may earn them a reputation for being uncooperative.

In sum, attention to the pragmatics of speech acts implies that the linguistic communication of emotion involves more than the indirect transmission of semantic meaning (whether by activation of cognitive scripts or context-dependent multimodal representations). When emotion words are delivered as part of verbal statements, they can also perform social actions such as allocating blame or threatening negative consequences, which encourage complementary or convergent responses from addressees. Thus, talking emotionally involves aligning people's relations towards what is happening and not simply trying to pin down the semantic features of a prior private experience. Words are constituents of emotional actions performed in the social world and not merely indirect representations of internal states. When emotional statements are backed up with the mobilization of the body in readiness to follow through on any implied commitment to act, their communicative force is further reinforced.

\section{Facial Communication}

As with emotion words, a popular psychological approach to facial expressions presupposes that they represent private meanings. In many studies, participants are presented with photographs of static facial configurations that have been preselected precisely because Western perceivers consistently allocate them to basic emotion categories (e.g., Ekman et al., 1969). Participants are then asked what emotion each picture represents. However, even evidence collected using this loaded methodology suggests that people from different societies often disagree about the emotional meaning of facial stimuli, sometimes quite dramatically (e.g., Crivelli et al., 2016; Gendron et al., 2018). Despite the fact that some facial configurations carry strong conventionalized associations with emotion concepts within Western societies and beyond, perceivers still may not spontaneously extract specifically emotional information from them (e.g., Gendron et al., 2018). Perhaps then the primary function of these faces is not to express emotions after all.

One of the practical reasons why faces adopt certain configurations in the first place is to get people ready to engage in 
certain forms of action directed at other people or at things happening in the shared environment (e.g., Parkinson, 2017). Muscles tense and eyes either focus on or avoid certain objects in preparation for addressing what is happening. It therefore seems possible that perceivers respond to the action tendencies embodied in facial configurations rather than the emotions they supposedly represent (Frijda, 1986; Frijda \& Tcherkassof, 1997). For example, someone scrunching up their nose appears to be rejecting a noxious stimulus, and someone with a fixed stare and pressed-together lips looks ready to burst into exertion directed at removing the obstacle in front of them. In both cases, the orientational implications of the facial configurations become more apparent when the object targeted by the action tendency is also perceptually available. Seeing someone scrunch their nose up when presented with food, or stare and press their lips together when confronted by another person, provides a clearer indication of what they are about to do and where their action will be directed. Indeed, being with someone in a mutually meaningful context while their embodied orientation to an object develops in real time may permit more direct complementary or resistant adjustments to their emerging stance. In other words, facial movements are part of emotional processes that are inherently relational rather than attached to any single individual.

Facial movements not only prepare for relational action but also function as signals that the person is ready to act in a certain way. For example, pulling an about-to-attack face may lead an antagonist to back off if they want to avoid an actual fight. Like verbal statements about emotions, facial movements can thus be warnings, threats, or invitations, as well as preparatory adjustments (e.g., Scarantino, 2017). A related analysis of the communicative and action-related functions of facial activity was developed by Fridlund (1994), who took his inspiration from the behavioural ecology of animal communication (e.g., Dawkins \& Krebs, 1978; Hinde, 1981). Fridlund argued that facial displays signal behavioural intentions or (more generally) social motives to conspecifics. According to him, their purpose is to communicate what the person is about to do or what they want the addressee to do, rather than to express any private emotional meaning.

As with emotion words, a fuller understanding of how facial movements operate requires attention to their deployment in unfolding interactions with other people. When facial activity is registered in realistic contexts, its interpersonal effects depend on the face's dynamic relation to what is happening around it, including the activities and orientations of those people at whom the facial display or action is directed. And when two or more people are directly interacting with one another, the functional significance of facial activity emerges as a consequence of interpersonal negotiation and mutual adjustment in a reciprocally relational process.

Facial movements are better equipped than words to present a continuous stream of activity that is dynamically attuned to ongoing events and other people's own unfolding reactions to those events. For this reason, facial activity can achieve more varied and more context-sensitive interpersonal functions.
However, research investigating the interpersonal effects of facial movements typically presents participants with static pictures (similar to those used in the judgement studies discussed earlier) and excludes any possibility of direct interaction with the person whose face is presented. The next section suggests ways in which this kind of research might be extended to give a fuller and more realistic picture of what happens when one person's emotions affect another person.

\section{Interpersonal Effects}

How do our emotions affect other people? Two explanations are commonly distinguished (e.g., Parkinson, 2011; van Kleef, 2009; Wróbel \& Imbir, 2019). The first proposes that Person A's emotional expressions induce matching or conflicting responses in Person B (mimicry or countermimicry). These induced responses in turn bring consequences for Person B's emotional experience by producing emotionally diagnostic interoceptive feedback (primitive emotion contagion; Hatfield et al., 1994). For example, I may smile automatically in response to your happy smile and the internal signals generated by my smile may make me feel happier too. The second explanation focuses on the perceived meaning of Person A's emotional response to an object or event. Person B registers the implied appraisal and makes corresponding adjustments to their own appraisal of what is happening (social appraisal; Manstead \& Fischer, 2001). For example, I may perceive your smile as an indication that you approve of what is happening and consequently conclude that the event is worthy of my approval, thus making me feel happier about it too. If Person B responds emotionally to Person A's emotion, their emotional response depends on feedback processes according to the primitive emotion contagion account, or on appraisal processes according to the social appraisal account. In either case, social influence supposedly depends on individualized rather than socially distributed processes.

I remain unconvinced of the viability of the primitive emotion contagion account of emotion's interpersonal effects (see Parkinson, 2011). For one thing, the evidence that emotions can be induced by bodily or facial feedback is at best limited (e.g., Coles et al., 2019), and often susceptible to alternative explanations (e.g., in terms of demand characteristics, or the relative degree of effort or discomfort associated with holding different facial positions). And even if interoceptive feedback produced stronger and more consistent effects, it is not clear that it provides the kind of signal that is capable in principle of generating a specifically emotional experience, including the characteristic sense of pleasure or displeasure and the associated motivational impulses (Reisenzein \& Stephan, 2014).

There are also good reasons for doubting that facial and postural movements have a close enough association with distinct emotions to provide diagnostic information to the perceiver in the first place. For example, Durán et al.'s (2017) meta-analysis of laboratory and field studies suggested that the facial configurations predicted by Ekman's (1972) neurocultural theory are observable in only around a quarter of sampled emotional situations, making it seem unlikely that internally perceived facial 
signals are able to specify the precise nature of the emotion a person might be experiencing.

Social appraisal provides a more workable explanation of interpersonal influence, and solid evidence supports many aspects of its operation. First, appraisal plays a more established causal role in emotion production (e.g., Roseman \& Evdokas, 2004; Speisman et al., 1964) than interoceptive feedback. Second, studies have shown that information about someone else's object-directed emotion can affect participants' attributions (e.g., van Doorn et al., 2015), attitudes (e.g., van Kleef et al., 2015), and appraisals (e.g., Hess \& Hareli, 2018). Putting these processes together makes it seem likely that people sometimes work backwards from their perception of someone else's emotion to infer corresponding appraisals, and that these inferred appraisals are in turn capable of affecting those people's own emotional orientation to events (backtracking: Elfenbein, 2007; reverse engineering: Hareli \& Hess, 2010; or reverse appraisal: de Melo et al., 2014).

Inferential social appraisal of this kind constitutes one possible variety of relation alignment. It explains how two or more people's emotional orientations to events may converge or diverge based on the one-way transmission of appraisal-related information. Such a process is encouraged by experimental manipulations that explicitly present participants with verbal or facial messages about a stimulus person's categorical emotion. For example, when told to imagine that a friend is angry about a recent car accident and asked to attribute responsibility for that event, participants are led to conclude that someone else was to blame (van Doorn et al., 2015). But does the same kind of reverse engineering fully explain all of emotion's interpersonal effects in contexts where people interact with each other more directly?

A particular issue with most research into inferential social appraisal is that it focuses only on what happens after participants have registered someone else's consolidated emotion either in the form of a verbal statement or preselected basic emotion expression. In many situations outside the laboratory, emerging emotional orientations to events already entrain other people's orientations before they coalesce into coherent emotional experiences or facial configurations. Senders and receivers may adjust moment by moment to each other's object-directed gaze patterns and bodily movements. Indeed, a process of nonverbal negotiation may produce a coregulated dynamic equilibrium (e.g., Fogel et al., 1992) that is not necessarily ever categorized in emotional terms by either party. Researchers need to devote more attention to the socially attuned processes that shape the sender's presentation of emotional information in the first place.

For example, Sorce et al.'s (1985) classic social referencing study showed that toddlers refrained from crossing a visual cliff when their mother displayed a "fear" face. However, the mother's expression was not simply a piece of information presented to the toddler in the abstract. Instead, the mother regulated her expression in real time, delivering it specifically at moments when the toddler looked in her direction for clarification of the ambiguous situation. The toddler was already oriented to the visual cliff as a potential barrier, and already oriented to their mother at the other side of it before the emotional communication took place. Their orientation then adjusted to their mother's dynamically presented stance towards the precipice as they tentatively moved forwards. They registered her widening eyes and gasping mouth in relation to what was happening and what they were trying to do. At some point in this process, a specific emotional meaning may have consolidated, but if so, it depended on cognitive and representational processes that were distributed between the two parties to the interpersonal exchange, rather than either individual's private sense-making activity in and of itself.

Most social referencing studies still involve explicit manipulation of categorical emotion communications. The referee is typically instructed to express fear, anger, or another discrete emotional state, and sometimes coached in how to deliver that expression "correctly." Studies that have investigated unmanipulated emotional expressions generally find that appraisals and appraisal inferences cannot fully explain reported social effects (e.g., Bruder et al., 2012; Parkinson \& Simons, 2009), suggesting that less explicit, noninferential processes may also be in operation.

Despite the interesting questions raised by research using more ecologically valid methods, most studies of emotion's interpersonal effects continue to focus on processes activated by a preexisting emotion, thus downplaying the issue of how that emotion itself might be interpersonally attuned and responsive in the first place. In research of this kind, emotional influence flows from Person A to Person B by design, with minimal opportunities for interpersonal interactivity or feedback. Outside these restrictive laboratory settings, however, interactants are often attuned specifically to the effects their emotions are having on each other. The concern that originally motivated their emotion makes a difference to how their orientations adjust to developing interpersonal responses. This means that we cannot fully understand emotion's social effects without considering its prior social-regulatory functions and how these functions are achieved in practice. The next section addresses these issues.

\section{Regulation and Regulatory Function}

Social referencing studies imply that a person's presentation of emotion may sometimes be part of an attempt either to convey emotional information or to influence someone else's behaviour more directly. For example, I may work up my anger to make you see that your actions are blocking my goals or to threaten punishment for your misbehaviour. In situations such as this, people seem able to draw on their experience of how emotions affect other people when tailoring their orientation in a way that maximizes its social influence.

Does regulation make a difference to the processes underlying emotion's interpersonal effects? According to inferential accounts, what matters is how emotion information is interpreted at the time it is delivered. Perceivers may factor in the possibility that a person had strategic reasons for working up or playing down their emotions when communicating to others 
(e.g., Shore \& Parkinson, 2018), but the inferential mechanism remains the same regardless. However, when interactants regulate emotions in real time with the specific purpose of exerting social influence, the resulting words and expressions are likely to be attuned and dynamically responsive to ongoing interpersonal feedback indicating the effectiveness of the intended influence. In other words, regulators may adjust their emotions on-line to maximize their interpersonal effects. For example, if my initial display of irritation does not stop you doing what I want you to stop doing, I may need to deploy less subtle tactics to get you to notice my disapproval and take it more seriously (e.g., Parkinson, 2001).

Along similar lines, caregivers in social referencing situations use directed patterns of gaze that capitalize on the addressee's perceived attention in order to indicate clearly that their communicated fear concerns a particular object in the environment. Alternated attempts to establish eye contact with the toddler further convey that the caregiver's object-oriented gaze carries implications that they should also attend to. In other words, Person A's communication is specifically modulated to influence Person B's understanding of what is happening (Clément \& Dukes, 2017). In order to achieve this didactic purpose, the communicator needs to attend to how the addressee responds and make any necessary adjustments to their delivery of relevant information.

In social referencing studies, toddlers usually defer to a trusted caregiver's communicated appraisal. However, emotion presentations do not necessarily produce their intended interpersonal effects if the addressee has a different agenda or is otherwise resistant to influence. The bidirectionality of the influence process can thus add further complications to the process of regulated emotional influence. For example, in some interactive situations, the implications of each party's emotion presentation may be ambiguous, potentially leading to mismatched interpersonal regulation attempts. Parkinson et al.'s (2016) study of interpersonal worry regulation in heterosexual relationships helps to illustrate this kind of calibration failure. These investigators argued that expressing worry to a romantic partner has at least two possible social-regulatory functions. First, it may be part of an attempt to solicit reassurance and emotional support. In this case, the desired and appropriate responses is for the partner to suppress any reciprocal expression of anxiety and engage in a regulatory strategy of interpersonal calming. Second, worry may be presented in order to draw a partner's attention to something potentially threatening on the horizon (interpersonal alerting). In this case, the desired and appropriate interpersonal response is to express more worry rather than less.

Interpersonal calming is likely to backfire when your partner's expressed worry is part of an interpersonal alerting attempt rather than a request for a comforting response. If your partner is trying to get you to take a threat more seriously, then any apparent reduction in your worry suggests that their regulatory attempt is failing to achieve its purpose. They may therefore work up their own worry even more. In response, you may intensify your attempt to show calm in order to contain their evidently increasing worry. Ultimately, interactions following this pattern may produce an escalating spiral of mismatched interpersonal emotions and mistargeted emotion regulation. Consistent with this account, Parkinson et al. (2016) found that participants' levels of interpersonal alerting were reliably predicted by their partners' tendency to use reappraisal to downregulate their negative emotions. Thus, participants apparently responded to their partner's attempts to minimize the seriousness of a worrying concern by upregulating their own presentation of worry.

The examples of interpersonal regulation considered so far serve the purpose of aligning emotional orientations towards an object, event, or mutual concern. Do similar processes also operate when an emotion is directed at the person who is trying to regulate it? For example, what happens when I attempt to downregulate someone else's anger that is directed at me rather than at someone else? To achieve my goal, I may need to work up complementary emotions such as guilt or sympathy instead of simply moderating my own anger.

Biglan et al. (1985) investigated interpersonal regulation of this kind by comparing problem-solving interactions of couples experiencing differing levels of marital distress. The investigators focused on behavioural sequences in which one partner's emotion-related behaviour apparently affected the other partner's immediate response. In distressed couples, wives presented relatively fewer depressive symptoms in the moments immediately following their husband's aggressive behaviour, suggesting that husbands of depressed wives might use anger to regulate their wives' depression in real time (coercion). However, husbands were also relatively less aggressive immediately after their wives' presentation of depressive symptoms, suggesting that wives' presentation of depressed emotion may in turn have regulated the anger that was being directed at them (appeasement).

Overall et al. (2014) presented evidence that relationship partners explicitly upregulate negative emotion expressions in order to solicit more sympathetic interpersonal responses. Their research focused on participants with an anxious attachment style (e.g., Bowlby, 1973) characterized by chronic fear of rejection by other people and acute sensitivity to the possibility of abandonment. Anxiously attached individuals tend to respond to threats to their close relationships by actively seeking support and reassurance from the other party. Overall et al. (2014) induced relationship threat by asking couples to discuss what each partner wanted the other partner to improve. Independent judges then reviewed the videotapes and coded indications that participants were trying to make their partners feel guilty (e.g., Vangelisti et al., 1991) by exaggerating their expressions of feeling hurt (e.g., pouting or sulking, emphasizing how their partner's behaviour was affecting them negatively, or reminding partners of their relational obligations).

Anxiously attached participants reported greater hurt feelings, and their hurt feelings were more strongly associated with attempts to upregulate their partner's guilt (as observed in the videotapes). Partners responded to participants' upregulated hurt expressions by becoming more guilty as intended. In other words, participants who felt threatened by implied criticism made themselves appear more hurt in order to make their partners feel more guilty. Successful interpersonal upregulation of 
partners' guilt, in turn provided participants with reassurance that their partners cared about the relationship, thus reducing their anxiety about rejection.

The strategic considerations motivating interpersonally attuned emotion communication may also come into play when neither party is explicitly trying to work up or play down their emotions. According to many social functional accounts (e.g., Fischer \& Manstead, 2016; Keltner \& Haidt, 1999; Parkinson, 1996), the purpose of certain emotions is precisely to influence other people in the first place. Thus, anger may already be a means of changing other people's unwanted behaviour, with a built-in sensitivity to interpersonal feedback regarding its success in achieving this purpose (Parkinson, 2001). Distinguishing emotion regulation from regulatory emotion is notoriously difficult both in theory and practice (e.g., Burkitt, 2018; Campos et al., 2004; Kappas, 2011). However, what seems clear is that a person's emotions can have interpersonally attuned interpersonal effects even when there is no explicit intention to achieve these effects. Perhaps then, strategic regulation of emotion for the purposes of social influence is simply an extension of a less articulated process of relation alignment that operates more generally in our emotional lives.

\section{Beyond Dyads}

\section{Intragroup Processes}

In addition to regulating interpersonal relations, emotions can also bring larger numbers of people closer together or further apart (e.g., Bruder et al., 2014; Fischer \& Manstead, 2016). When individuals have similar emotional orientations to what is happening, this potentially implies that they also share a common social identity with you (e.g., Livingstone et al., 2011). Conversely, categorizing others as ingroup members increases their capacity to influence your own emotional orientation (because you want to feel that you belong to the group [e.g., Turner et al., 1989] and because you want other ingroup members to like you [e.g., Deutsch \& Gerard, 1955]). Under certain circumstances, the reciprocal influences of intragroup social appraisal and of commonality of emotional orientation produce a positive feedback loop that reinforces a sense of mutual allegiance and solidarity (e.g., Neville \& Reicher, 2011). When group members work together on practical tasks, the sense that their combined effort improves the chances of success may further generate a sense of collective efficacy (e.g., Drury et al., 2005).

As the number of people coming together rises, the mutually reinforcing effects of these processes may correspondingly increase. When we are entirely surrounded by other people who share a common emotional orientation, our emotions may start to seem all-encompassing and part of a genuinely collective experience (e.g., von Scheve \& Ismer, 2013). Because no one around us dissents from the common cause, immersion in the social reality created by the group's evident appraisals intensifies.

For centuries, many social theorists have attributed the emotional effects of mass gatherings to contagious processes. For example, LeBon (1895/1947) believed that crowds sup- press rationality and increase suggestibility, thereby making their members more susceptible to emotional influence by the people around (see Reicher, 1987, for a critique). Seventeen years later, Durkheim (1912/1995) developed the concept of collective effervescence to account for the positive emotional experiences that emerge among copresent crowd members. According to him,

$[T]$ he very act of congregating is an exceptionally powerful stimulant. Once the individuals are gathered together, a sort of electricity is generated from their closeness and quickly launches them to an extraordinary height of exaltation. Every emotion expressed resonates without interference. (p. 217)

Both LeBon's (1895/1947) and Durkheim's (1912/1995) accounts imply that low-level noninferential processes of reciprocal adjustment contribute to the consolidation of collective emotions in crowds.

According to Collins (2004), Durkheimian effervescence is specifically reinforced by structured activities that impose a rhythm and tempo on crowd members' activities (i.e., zeitgebers) and facilitate mutual entrainment of their movements (McGrath \& Kelly, 1986). Repeated patterns provide a common focus and a predictability that makes it easier for people to join in with whatever others are doing. A clear and simple example is provided by the "muscular bonding" achieved by military personnel marching in time and in a common direction (McNeill, 1995 , p. 2). Other more articulated communal activities also encourage temporal coordination of physical activity (e.g., Henriques, 2010), thus consolidating the sense of being, moving, and working together (the "corporeal experience of solidarity"; Collins, 2004, p. 48).

Collins (2014) argues that these "interaction rituals" can serve the specific function of helping people to share their emotions. Shared emotions then intensify as a result of reciprocal social feedback and are transformed by the resulting sense of intersubjective empowerment. Thus, mutual entrainment of dynamically structured emotional orientations may contribute to an implicit sense of unity that facilitates emotional influence. In other words, processes of group-based appraisal or social identification need not operate at an inferential level to produce collective emotions.

The kind of "contagious" process proposed by Durkheim (1912/1995) and Collins (2014) need not involve the interoceptive registration of bodily response implied by Hatfield et al.'s (1994) primitive emotion contagion model. Because crowd members sense the commonality of their emotional orientation, they can pick up the emotional quality of their own engagement with events directly from the facial and bodily activities of the people around them. Any feedback may thus come from socialrelational rather than internal sources.

\section{Social Position}

Group members are not fully interchangeable individuals: Some are in a position to exert greater emotional influence than others. One important factor that puts people in such a position of 
power is group prototypicality (e.g., Turner et al., 1989), defined as the extent to which members represent the valued characteristics of the group. A prototypical group member, then, is one who embodies defining qualities that make a group superior on dimensions that matter to its members. Prototypicality is associated with greater social influence because ingroup members are motivated to bring their orientations into line with perceived group norms which (by definition) are best represented by prototypical group members (e.g., Hains et al., 1997).

The social influence exerted by prototypical members is not only likely to be stronger but also to spread more widely. Prototypicality depends on the extent to which a group member's attitudes and values are shared with other group members. Sharing attitudes and values, in turn, increases interpersonal attraction and affiliation (e.g., Byrne, 1961). Thus, more prototypical group members come into contact with larger numbers of ingroup members, and these ingroup members are more motivated to share their orientations. Their network centrality (Wölfer et al., 2015) facilitates intragroup influence (e.g., Kameda et al., 1997; Venkataramani et al., 2010). Taken together, these considerations also make it more likely that prototypical group members get nominated and selected for leadership positions (e.g., Hogg \& van Knippenberg, 2003), which potentially increase their capacity to influence other group members and their emotions still further.

Leaders may also exploit their relational position strategically in order to influence other group members' emotions. They may work up group-sanctioned emotions to make themselves appear more prototypical and to reinforce followers' levels of group identification, which in turn makes those followers more susceptible to emotional influence. In other words, access to social resources may allow an individual to use their emotions to bring other group members into line. Group leaders may also have the power to organize group activities that are structured in ways that encourage reciprocal entrainment of group members' movements and gestures or that generate a sense of collective efficacy, thus potentially promoting collective emotions that depend on less explicit processes. Examples are the kinds of team-building exercises used in managementsanctioned away days. In service industries, leaders can similarly institute regimes that encourage employees to work up organizationally approved emotions and avoid presenting organizationally inappropriate emotions during their interactions with clients (e.g., Grandey, 2000; Hochschild, 1983). Thus, social position may permit a form of emotion regulation by proxy, meaning that leaders need not perform the required emotional labor themselves.

However, intragroup emotional influence does not only flow in one direction from leaders to followers (and potentially beyond to clients and consumers). In fact, group emotion norms can also change as a consequence of negotiation or active resistance from group members with less powerful social positions. Prototypicality and influence potential may therefore be reconfigured. Leaders' awareness that power may potentially get snatched away may lead them to moderate its exertion in anticipation of future retaliation by others who may acquire power at some later stage. Correspondingly, the possibility of gaining power may encourage relatively less powerful people to defy emotional demands delivered by powerful people whose influential positions seem unstable or difficult to sustain. Taken together, these social dynamics suggest that people whose power is insecure need to monitor subordinates' motives and behaviour in order to detect potential threats to their currently powerful position (Keltner et al., 2003). In particular, they may become sensitive to hostile intentions conveyed by subordinates' anger (Stamkou et al., 2016). If power is built on unsteady foundations, then the anger of the previously powerless may sometimes have the capacity to unsettle things to a relatively greater extent.

\section{Emotion as Relational Orientation}

In this article, I have developed the argument that emotions serve to align people's orientations to one another and to objects and events in their shared environment. I have also explored the implications of this argument for our understanding of emotion's interpersonal and intragroup effects, and of how emotions serve strategic functions in dyadic, group, and organizational settings. My starting assumption was that emotions are relational processes rather than private mental states. In this final section, I discuss what relationality implies in further detail and consider whether the relations aligned by emotions are always and exclusively social relations.

Most theorists accept that evaluative intentionality is a defining characteristic of emotion (e.g., Gordon, 1974): Emotions are always about something, and always involve positive or negative orientations to the thing they are about. For example, anger involves being unfavorably disposed towards some force that impedes one's activities or goals. At one level, the evaluative orientation that characterizes any emotion may involve internal mental processes such as cognitive appraisals of whatever is happening (e.g., Lazarus, 1991). However, the object-directedness of emotional conduct also implies focused activity of the body and its sensory organs (Arnold, 1960). Our limbs and muscles respond to the pulls and pressures exerted by the material and social world. We actively collect or reject different kinds of information about what is going on around us using our eyes, ears, nose, and skin. We take specific stances towards particular aspects of the situation, and these stances adjust as the situation changes. We lean towards or away from something, stare at it or look away. We brace ourselves against the shock of contact or huddle into a protective ball.

Emotional orientations of this embodied variety are inherently relational because they depend not only on the individual's own attentional attunement and action readiness, but also on wherever that individual's attention and action are directed to (e.g., Frijda, 1986). This relationality is social when emotions are either directly oriented at other people or oriented to other people's orientations to social or nonsocial objects. However, even when an emotion's primary object does not directly involve anyone else, its orientation often relates to someone else's orientation in other ways. As social animals, humans are acutely 
sensitive to what other humans think and feel about what they do. And because a great number of nonsocial objects are first encountered during the extended neotenous period when human infants stay in close contact with caregivers, inclinations to approach or avoid those objects are socially cultivated and conditioned from the outset.

Emotional orientations are necessarily dynamic as well as relational. They adjust to the changing forces presented by the objects, events, and people at which they are directed. When people are orienting emotionally to another person's actions, that person's ongoing responsivity to their orientation is an interlocking component of the relation-alignment process. Even emotional objects that are not intrinsically social can actively facilitate or impede relational agendas (cf. Latour, 2005). Approach and avoidance movements may need to recalibrate as their target gets closer or further away, or when obstacles to those movements need to be displaced. When someone gets angry with a car or computer, it is often because it refuses to let them get where they are trying to go.

When emotions are about recalled, imagined, or anticipated situations, their dynamic embodied aspects may be less evident (e.g., Stemmler, 1989). However, we still make physical adjustments as we run through alternative simulations of how the episode might turn out. We hold private conversations and rehearse possible ways of coping with things. And we often share our conjectural positions with others in order to recalibrate perspectives or try out possible ways through. In other words, the capacity to become emotionally engaged with a virtual situation depends at least in part on prior experience of engagement with relational forces and contingencies that are more imminent and directly pressing.

When our orientation is part of a directly engaging interaction with someone else, many of its interpersonal effects emerge from mutual dynamic adjustments in the lines of action that both of us are pursuing. When we are focusing on some nonsocial event during an interpersonal interaction, our respective orientations may become more or less coordinated as a function of unfolding nonverbal negotiations and recalibrations. In both cases, our orientational movements and social signals may also carry implications that go beyond the immediate situation. Other people respond to the symbolic meanings and anticipated pragmatic consequences of our relational orientations, as well as the more direct pressures and affordances that they present.

\section{Conclusions}

If emotions start out wholly inside an individual's mind or brain, then their impact on the social world is necessarily indirect. According to a popular view, human infants are born with hardwired neural programs that produce the private experience of a number of discrete affective states. The expression of these states can then be registered by others who respond to their recognizable meanings. Older children subsequently acquire the capacity to represent these emotions in words, although those words may not fully capture the underlying qualities of their subjective feelings. Because the emotions themselves remain private, any functional effects on other people depend on their imperfect translation into publicly available movements, signals, and symbols.

By contrast, I have argued that emotion words and faces are means of achieving social influence and not just representations of prior internal states (see also Crivelli \& Fridlund, 2018). Some influence processes depend on emotional meaning and inference, while others result from the dynamic calibration and recalibration of orientational movements and cues. Strategic regulation of other people's responses may similarly involve a wide range of operations that need to be flexibly responsive to the other person's changing orientation to be effective.

Where does emotion itself fit into this picture? The evidence suggests that there is no distinctive set of internal sensations or perceptions that define the quality of what we experience when we get emotional (e.g., Barrett, 2017). Instead, emotion emerges from the unfolding process of engaging with social events. We do not need to be conscious of bodily symptoms of any kind in order to orient to the world in an emotional way. What it feels like to be emotional, then, is usually the sense of things pressing against us or pulling us along as we navigate our way through (e.g., Frijda, 2005). Any emotional meaning that we or others attribute to our relational orientation is secondary to its central function as a mode of influence. We can't get to the heart of the phenomenon by looking ever deeper inside.

\section{Declaration of Conflicting Interests}

The author declared no potential conflicts of interest with respect to the research, authorship, and/or publication of this article.

\section{ORCID iD}

Brian Parkinson (iD https://orcid.org/0000-0001-8065-5725

\section{References}

Arnold, M. B. (1960). Emotion and personality: Vol. 1. Psychological aspects. Columbia University Press.

Austin, J. L. (1962). How to do things with words. Clarendon Press.

Barrett, L. F. (2017). How emotions are made: The secret life of the brain. Macmillan.

Bedford, E. (1957). Emotions. Proceedings of the Aristotelian Society, 57, 281-304.

Biglan, A. A., Hops, H., Sherman, L., Friedman, L. S., Arthur, J., \& Osteen, V. (1985). Problem-solving interactions of depressed women and their husbands. Behavior Therapy, 16(5), 431-451. https://doi.org/10.1016/ S0005-7894(85)80023-X

Bowlby, J. (1973). Attachment and loss: Vol. 2. Separation: Anxiety and anger. Hogarth Press.

Brown, P., \& Levinson, S. C. (1987). Politeness: Some universals in language usage. Cambridge University Press.

Bruder, M., Dosmukhambetova, D., Nerb, J., \& Manstead, A. S. R. (2012) Emotional signals in nonverbal interaction: Dyadic facilitation and convergence in expressions, appraisals, and feelings. Cognition and Emotion, 26(3), 480-502. https://doi.org/10.1080/02699931.2011.645280

Bruder, M., Fischer, A. H., \& Manstead, A. S. R. (2014). Social appraisal as a cause of collective emotions. In C. von Scheve \& M. Salmela (Eds.), Collective emotions (pp. 141-155). Oxford University Press.

Bühler, K. (2011). Theory of language: The representational function of language (D. Fraser Goodwin in collaboration with A. Eschbach, Trans.). John Benjamins Publishing Company. (Original work published 1934) 
Burkitt, I. (2018). Decentring emotion regulation: From emotion regulation to relational emotion. Emotion Review, 10, 167-173. https://doi. org $/ 10.1177 / 1754073917712441$

Byrne, D. (1961). Interpersonal attraction and attitude similarity. Journal of Abnormal and Social Psychology, 62(3), 713-715. https://doi. org $/ 10.1037 / \mathrm{h} 0044721$

Campos, J. J., Frankel, C. B., \& Camras, L. (2004). On the nature of emotion regulation. Child Development, 75(2), 377-394. https://doi. org/10.1111/j.1467-8624.2004.00681.x

Clément, F., \& Dukes, D. (2017). Social appraisal and social referencing: Two components of affective social learning. Emotion Review, 9, 253261. https://doi.org/10.1177/1754073916661634

Coles, N. A., Larsen, J. T., \& Lench, H. C. (2019). A meta-analysis of the facial feedback literature: Effects of facial feedback on emotional experience are small and variable. Psychological Bulletin, 145(6), 610-651. https://doi.org/10.1037/bu10000194

Collins, R. (2004). Interaction ritual chains. Princeton University Press.

Collins, R. (2014). Interaction ritual chains and collective effervescence. In C. von Scheve \& M. Salmela (Eds.), Collective emotions (pp. 299 311). Oxford University Press.

Crivelli, C., \& Fridlund, A. J. (2018). Facial displays are tools for social influence. Trends in Cognitive Sciences, 22(5), 388-399. https://doi. org/10.1016/j.tics.2018.02.006

Crivelli, C., \& Fridlund, A. J. (2019). Inside-out: From basic emotions theory to the behavioral ecology view. Journal of Nonverbal Behavior, 43, 161-194. https://doi.org/10.1007/s10919-019-00294-2

Crivelli, C., Jarillo, S., Russell, J. A., \& Fernández-Dols, J.-M. (2016). Reading emotions from faces in two indigenous societies. Journal of Experimental Psychology: General, 145(7), 830-843. https://doi. org/10.1037/xge0000172

Dawkins, R., \& Krebs, J. R. (1978). Animal signals: Information or manipulation. In J. R. Krebs \& N. B. Davies (Eds.), Behavioural ecology: An evolutionary approach (pp. 282-309). Blackwell Scientific.

De Melo, C. M., Carnevale, P. J., Read, S. J., \& Gratch, J. (2014). Reading people's minds from emotion expressions in interdependent decision making. Journal of Personality and Social Psychology, 106(1), 73-88. https://doi.org/10.1037/a0034251

De Rivera, J., \& Grinkis, C. (1986). Emotions as social relationships. Motivation and Emotion, 10(4), 351-369. https://doi.org/10.1007/ BF00992109

Deutsch, M., \& Gerard, H. B. (1955). A study of normative and informational social influences on individual judgment. Journal of Abnormal and Social Psychology, 51(3), 629-636. https://doi.org/10.1037/ h0046408

Drury, J., Cocking, C., Beale, J., Hanson, C., \& Rapley, F. (2005). The phenomenology of empowerment in collective action. British Journal of Social Psychology, 44(3), 309-328. https://doi.org/10.1348/ $014466604 X 18523$

Durán, J. I., Reisenzein, R., \& Fernández-Dols, J.-M. (2017). Coherence between emotions and facial expressions: A research synthesis. In J.-M. Fernández-Dols \& J. A. Russell (Eds.), The science of facial expression (pp. 107-129). Oxford University Press.

Durkheim, É. (1995). The elementary forms of religious life (K. E. Fields, Trans.). Free Press. (Original work published 1912)

Edwards, D. (1999). Emotion discourse. Cultural Psychology, 5(3), 271291. https://doi.org/10.1177/1354067X9953001

Ekman, P. (1972). Universals and cultural differences in facial expressions of emotion. In J. Cole (Ed.), Nebraska Symposium on Motivation (pp. 207-283). University of Nebraska Press.

Ekman, P., Sorensen, E. R., \& Friesen, W. V. (1969). Pan-cultural elements in facial displays of emotions. Science, 164(385), 86-88. https://doi. org/10.1126/science. 164.3875 .86

Elfenbein, H. A. (2007). Emotion in organizations: A review and theoretical integration. Academy of Management Annals, 1(1), 371-457. https:// doi.org/10.1080/078559812
Fehr, B., \& Russell, J. A. (1984). Concept of emotion viewed from a prototype perspective. Journal of Experimental Psychology: General, 113(3), 464-486. https://doi.org/10.1037/0096-3445.113.3.464

Fischer, A. H., \& Manstead, A. S. R. (2016). Social functions of emotion and emotion regulation. In L. F. Barrett, M. Lewis, \& J. M. HavilandJones (Eds.), Handbook of emotions (4th ed., pp. 424-439). The Guilford Press.

Fogel, A., Nwokah, E., Dedo, J. Y., Messinger, K., Dickson, K. L., Matusov, E., \& Holt, S. A. (1992). Social process theory of emotion: A dynamic systems approach. Social Development, 1(2), 122-142. https://doi. org/10.1111/j.1467-9507.1992.tb00116.x

Fridlund, A. J. (1994). Human facial expression: An evolutionary view. Academic Press.

Frijda, N. H. (1986). The emotions. Cambridge University Press.

Frijda, N. H. (2005). Emotion experience. Cognition and Emotion, 19(4), 473-497. https://doi.org/10.1080/02699930441000346

Frijda, N. H., \& Tcherkassof, A. (1997). Facial expressions as modes of action readiness. In J. A. Russell \& J.-M. Fernández-Dols (Eds.), The psychology of facial expression (pp. 78-102). Cambridge University Press.

Gendron, M., Crivelli, C., \& Barrett, L. F. (2018). Universality reconsidered: Diversity in meaning making about facial expressions. Current Directions in Psychological Science, 27(4), 211-219. https://doi. org/10.1177/0963721417746794

Gordon, R. M. (1974). The aboutness of emotions. American Philosophical Quarterly, 11(1), 17-36.

Grandey, A. A. (2000). Emotional regulation in the workplace: A new way to conceptualize emotional labor. Journal of Occupational Health Psychology, 5(1), 95-110. https://doi.org/10.1037/1076-8998.5.1.95

Hains, S. C., Hogg, M. A., \& Duck, J. M. (1997). Self-categorization and leadership: Effects of group prototypicality and leader stereotypicality. Personality and Social Psychology Bulletin, 23(10), 1087-1099. https://doi.org/10.1177/01461672972310009

Hareli, S., \& Hess, U. (2010). What emotional reactions can tell us about the nature of others: An appraisal perspective on person perception. Cognition and Emotion, 24(1), 128-140. https://doi.org/10.1080/ 02699930802613828

Hatfield, E., Cacioppo, J. T., \& Rapson, R. L. (1994). Emotional contagion. Cambridge University Press.

Henriques, J. (2010). The vibrations of affect and their propagation on a night out on Kingston's dancehall scene. Body and Society, 16(1), 5789. https://doi.org/10.1177/1357034X09354768

Hess, U., \& Hareli, S. (2018). On the malleability of the meaning of contexts: The influence of another person's emotion expressions on situation perception. Cognition and Emotion, 32(1), 185-191. https://doi. org/10.1080/02699931.2016.1269725

Hinde, R. A. (1981). Animal signals: Ethological and games-theory approaches are not incompatible. Animal Behaviour, 29(2), 535-542. https://doi.org/10.1016/S0003-3472(81)80116-9

Hochschild, A. R. (1983). The managed heart: Commercialization of human feeling. University of California Press.

Hogg, M., \& van Knippenberg, D. (2003). Social identity and leadership processes in groups. Advances in Experimental Social Psychology, 35, 1-52. https://doi.org/10.1016/S0065-2601(03)01001-3

James, W. (1884). What is an emotion? Mind, 9(34), 188-205. https://www. jstor.org/stable/2246769

Kameda, T., Ohtsubo, Y., \& Takezawa, M. (1997). Centrality in sociocognitive networks and social influence: An illustration in a group decision-making context. Journal of Personality and Social Psychology, 73(2), 296-309. https://doi.org/10.1177/1368430200003002002

Kappas, A. (2011). Emotion and regulation are one! Emotion Review, 3, 17-25. https://doi.org/10.1177/1754073910380971

Keltner, D., Gruenfeld, D. H., \& Anderson, C. (2003). Power, approach, and inhibition. Psychological Review, 110(2), 265-284. https://doi. org/10.1037/0033-295X.110.2.265 
Keltner, D., \& Haidt, J. (1999). Social functions of emotions at four levels of analysis. Cognition and Emotion, 13(5), 505-521. https://doi. org $110.1080 / 026999399379168$

Kövecses, Z. (1990). Emotion concepts. Springer-Verlag.

Laird, J. D., \& Bresler, C. (1992). The process of emotional experience: A self-perception theory. In M. S. Clark (Ed.), Review of personality and social psychology: Vol. 13. Emotion (pp. 213-234). SAGE.

Latour, B. (2005). Reassembling the social: An introduction to actor-network theory. Oxford University Press.

Lazarus, R. S. (1991). Emotion and adaptation. Oxford University Press.

Le Bon, G. (1895/1947). The crowd: A study of the popular mind. Ernest Benn.

Levinson, S. C. (1983). Pragmatics. Cambridge University Press.

Livingstone, A. G., Spears, R., Manstead, A. S. R., Bruder, M., \& Shepherd, L. (2011). We feel, therefore we are: Emotion as a basis for selfcategorization and social action. Emotion, 11(4), 754-767. https://doi. org/10.1037/a0023223

Manstead, A. S. R., \& Fischer, A. H. (2001). Social appraisal: The social world as object of and influence on appraisal processes. In K. R. Scherer, A. Schorr, \& T. Johnstone (Eds.), Appraisal processes in emotion: Theory, methods, research (pp. 221-232). Oxford University Press.

McGrath, J. E., \& Kelly, J. R. (1986). Time and human interaction: Toward a social psychology of time. The Guilford Press.

McNeill, W. (1995). Keeping together in time. Harvard University Press.

Neville, F., \& Reicher, S. (2011). The experience of collective participation: Shared identity, relatedness and emotionality. Contemporary Social Science, 6(3), 377-396. https://doi.org/10.1080/21582041.201 2.627277

Overall, N. C., Girme, Y. U., Lemay, E. P., Jr., \& Hammond, M. D. (2014). Attachment anxiety and reactions to relationship threat: The benefits and costs of inducing guilt in romantic partners. Journal of Personality and Social Psychology, 106(2), 235-256. https://doi.org/10.1037/a0034371

Parkinson, B. (1996). Emotions are social. British Journal of Psychology, 87(4), 663-683. https://doi.org/10.1111/j.2044-8295.1996.tb02615.x

Parkinson, B. (2001). Anger on and off the road. British Journal of Psychology, 92(3), 507-526. https://doi.org/10.1348/000712601162310

Parkinson, B. (2011). Interpersonal emotion transfer: Contagion and social appraisal. Personality and Social Psychology Compass, 5(7), 428-439. https://doi.org/10.1111/j.1751-9004.2011.00365.x

Parkinson, B. (2013). Journeys to the center of emotion. Emotion Review, 5, 180-184. https://doi.org/10.1177/1754073912468168

Parkinson, B. (2017). Interpersonal effects and functions of facial activity. In J.-M. Fernández-Dols \& J. A. Russell (Eds.), The science of facial expression (pp. 435-456). Oxford University Press.

Parkinson, B. (2019). Social referencing in adults and children: Extending social appraisal approaches. In U. Hess \& S. Hareli (Eds.), The social nature of emotion expression: What emotions can tell us about the world (pp. 119-140). Springer.

Parkinson, B., \& Simons, G. (2009). Affecting others: Social appraisal and emotion contagion in everyday decision-making. Personality and Social Psychology Bulletin, 35(8), 1071-1084. https://doi. org/10.1177/0146167209336611

Parkinson, B., Simons, G., \& Niven, K. (2016). Sharing concerns: Interpersonal worry regulation in romantic couples. Emotion, 16(4), 449-458. https://doi.org/10.1037/a0040112

Pomerantz, A. (1984). Agreeing and disagreeing with assessments: Some features of preferred/dispreferred turn shapes. In J. M. Atkinson \& J. Heritage (Eds.), Structures of social action: Studies in conversation analysis (pp. 79-112). Cambridge University Press.

Potter, J., \& Wetherell, M. (1987). Discourse and social psychology: Beyond attitudes and behaviour. SAGE.

Reicher, S. D. (1987). Crowd behaviour as social action. In J. C. Turner, M. A. Hogg, P. J. Oakes, S. D. Reicher, \& M. S. Wetherell (Eds.), Rediscovering the social group: A self-categorization theory (pp. 171-205). Blackwell.
Reisenzein, R., \& Stephan, A. (2014). More on James and the physical basis of emotion. Emotion Review, 6, 35-46. https://doi.org/10.1177/ 1754073913501395

Roseman, I. J., \& Evdokas, A. (2004). Appraisals cause experienced emotions: Experimental evidence. Cognition and Emotion, 18(1), 1-28. https://doi.org/10.1080/02699930244000390

Russell, J. A., \& Fehr, B. (1994). Fuzzy concepts in a fuzzy hierarchy: Varieties of anger. Journal of Personality and Social Psychology, 67(2), 186-205. https://doi.org/10.1037/0022-3514.67.2.186

Sacks, H. (1992). Lectures on conversation. Volumes 1 and 2. Blackwell.

Scarantino, A. (2017). How to do things with emotional expressions: The theory of affective pragmatics. Psychological Inquiry, 28(2-3), 165185. https://doi.org/10.1080/1047840X.2017.1328951

Scarantino, A., \& Griffiths, P. (2011). Don't give up on basic emotions. Emotion Review, 3, 444-454. https://doi.org/10.1177/1754073911 410745

Schachter, S. (1964). The interaction of cognitive and physiological determinants of emotional state. In L. Festinger (Ed.), Advances in experimental social psychology (Vol 1, pp. 49-80). Academic Press.

Shaver, P., Schwartz, J., Kirson, D., \& O'Connor, C. (1987). Emotion knowledge: Further exploration of a prototype approach. Journal of Personality and Social Psychology, 52(6), 1061-1086. https://doi. org/10.1037/0022-3514.52.6.1061

Shore, D. M., \& Parkinson, B. (2018). Interpersonal effects of strategic and spontaneous guilt communication in trust games. Cognition and Emotion, 32(6), 1382-1390. https://doi.org/10.1080/02699931.2017. 1395728

Solomon, R. C. (2003). What is an emotion? Classic and contemporary readings (2nd ed.). Oxford University Press.

Sorce, J. F., Emde, R. N., Campos, J., \& Klinnert, M. D. (1985). Maternal emotional signaling: Its effect on the visual cliff behavior of 1-year-olds. Developmental Psychology, 21(1), 195-200. https://doi. org/10.1037/0012-1649.21.1.195

Speisman, J. C., Lazarus, R. S., Mordkoff, A., \& Davison, L. (1964). Experimental reduction of stress based on ego-defense theory. Journal of Abnormal and Social Psychology, 68(4), 367-380. https://doi. org $/ 10.1037 / \mathrm{h} 0048936$

Stamkou, E., van Kleef, G. A., Fischer, A. H., \& Kret, M. E. (2016). Are the powerful really blind to the feelings of others? How hierarchical concerns shape attention to emotions. Personality and Social Psychology Bulletin, 42(6), 755-768. https://doi.org/10.1177/ 0146167216636632

Stemmler, G. (1989). The autonomic differentiation of emotions revisited: Convergent and discriminant validation. Psychophysiology, 26(6), 617-632. https://doi.org/10.1111/j.1469-8986.1989.tb03163.x

Turner, J. C., Wetherell, M. S., \& Hogg, M. A. (1989). Referent informational influence and group polarization. British Journal of Social Psychology, 28(2), 135-147. https://doi.org/10.1111/j.2044-8309.1989. tb00855.x

Van Doorn, E. A., van Kleef, G. A., \& van der Pligt, J. (2015). Deriving meaning from others' emotions: Attribution, appraisal, and the use of emotions as social information. Frontiers in Psychology, 6, Article 1077. https://doi.org/10.3389/fpsyg.2015.01077

Vangelisti, A. L., Daly, J. A., \& Rudnick, J. R. (1991). Making people feel guilty in conversations: Techniques and correlates. Human Communication Research, 18(1), 3-39. https://doi.org/10.1111/j.1468-2958.1991. tb00527.x

Van Kleef, G. A. (2009). How emotions regulate social life: The emotions as social information (EASI) model. Current Directions in Psychological Research, 18(3), 184-188. https://doi.org/10.1111/ j.1467-8721.2009.01633.x

Van Kleef, G. A., van den Berg, H., \& Heerdink, M. W. (2015). The persuasive power of emotions: Effects of emotional expressions on attitude formation and change. Journal of Applied Psychology, 100(4), 11241142. https://doi.org/10.1037/ap10000003 
Venkataramani, V., Green, S. G., \& Schleicher, D. J. (2010). Well-connected leaders: The impact of leaders' social network ties on LMX and members' work attitudes. Journal of Applied Psychology, 95(6), 1071-1084. https://doi.org/10.1037/a0020214

Von Scheve, C., \& Ismer, S. (2013). Towards a theory of collective emotions. Emotion Review, 5, 406-413. https://doi.org/10.1177/ 1754073913484170
Wölfer, R., Faber, N. S., \& Hewstone, M. (2015). Social network analysis in the science of groups. Group Dynamics: Theory, Research, and Practice, 19(1), 45-61. https://doi.org/10.1037/gdn0000021

Wróbel, M., \& Imbir, K. K. (2019). Broadening the perspective on emotional contagion and emotional mimicry: The correction hypothesis. Perspectives on Psychological Science, 10(3), 437-451. https://doi. org/10.1177/1745691618808523 